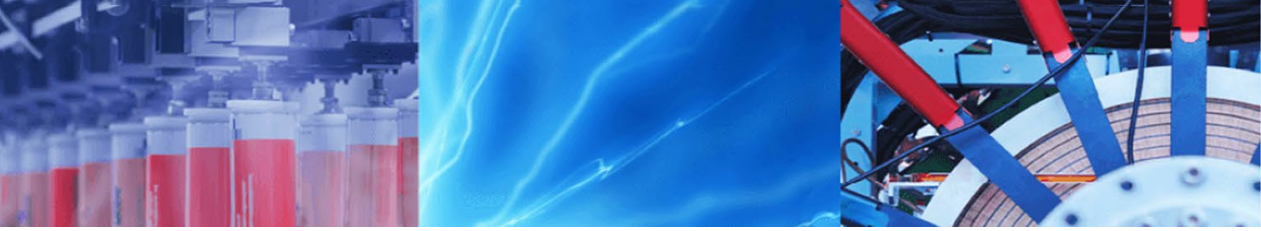

Research Article

\title{
Change in spectral properties of dyes upon immobilization on silicon surfaces: a combined theoretical and experimental study
}

\author{
Abhi Mukherjee ${ }^{1} \cdot$ Kishor G. Thorat $^{2} \cdot$ Nagaiyan Sekar $^{2} \cdot$ Siddhartha Panda $^{1}$ (I)
}

(c) Springer Nature Switzerland AG 2019

\begin{abstract}
Organic dyes, both in solution phase and in immobilized condition, are useful tools for optical detection. Studies have shown that spectral property of dyes in solution are different from that in the immobilized state. In this work, we have studied the optical properties of dyes in solution as well as in immobilized state with three categories of dyes, monocarboxylic mono-functional, bi-carboxylic bi functional and bi-carboxylic mono-functional. Two linkers (APTES and PEI) were used for attaching the dyes to the silanol terminated silicon surface. Geometries were optimized using density functional theory. Time dependant density functional theory was used to calculate the absorption spectra of free and attached dyes. B3LYP and CAM-B3LYP hybrid functional were used for the theoretical calculations. Experimental results showed that dyes upon immobilization experienced a large red shift in the absorption maxima. The value of the red shift in absorption maxima was comparable for both the linkers. Theoretical calculations indicated this large shift is not due to bond formation between dye and the linker. This leads to the conclusion that aggregation takes place between dye molecules upon immobilization but not in solution, and this causes the large red shift in the absorption maxima values of the immobilized dyes.
\end{abstract}

Keywords Dye · Immobilization · DFT · TDDFT · B3LYP.CAMB3LYP · Spectra · Linker · Aggregates

\section{Introduction}

Conjugated organic dyes, which can react with the desired chemical species with transduction into an optical signal show promise for use in optical sensors and other photonic applications [1-4]. For quick detection of analytes in labon-a-chip applications, the dyes need to be attached to a solid platform. The spectral behaviour of dyes attached to a solid platform is different from those in solution and this is attributed to possible changes in the molecular orientation as in some cases formation of J-aggregates or $\mathrm{H}$-aggregates on solid surfaces have been reported [5]. Thus, comparative studies of the change in spectral properties of the dyes in solution to that in an immobilised state are important. The several ways a molecule can be attached to a surface include physisorption, electrostatic interaction, attachment by affinity interaction and covalent bond formation [6]. Covalent bond formation between the dye molecule and the surface appears to be a better option than other modes of attachments mentioned above, as dyes attached via weaker modes of interaction tends to get removed while washing [5]. Dye molecules are immobilized on solid platforms through some specific functional group on the dye [5, 7-11] and typically carboxylic or phosphoric acid moieties on the dye have served this purpose well [12-15]. Linkers play an important role in tethering the dye molecules to the surface $[16,17]$. Thus along with the spectral properties of the dye molecules, the retention of dye molecules on surface also depends on the linker. Upon immobilization, there is

\footnotetext{
$\bowtie$ Nagaiyan Sekar, spanda@iitk.ac.in; $\varangle$ Siddhartha Panda, n.sekar@ictmumbai.edu.in | ${ }^{1}$ Department of Chemical Engineering, Indian Institute of Technology Kanpur, Kanpur 208016, India. ${ }^{2}$ Department of Dyestuff Technology, Institute of Chemical Technology, Mumbai 400019, India.
} 
a possibility of denaturation, agglomeration or aggregate formation $[18,19]$. The nature of the interaction between the dye molecule and the linker which affects the overall attachment process as well as spectral properties, need to be studied so as to help obtain optimal performance of the optical sensor.

Density functional theory (DFT) has been useful in predicting spectral properties and structure of molecules [20, 21]. Time dependant density functional theory (TDDFT) $[22,23]$ enables examination of the excited state of the molecules and thereby have better understanding of the changes that occur in the spectral properties of molecules and thus predict the absorption spectra [24,25]. Predicting the spectra of dye molecules, both in solution as well as those immobilised on a solid surface, provides valuable insights on the ideal nature of spectra and peak positions. These could help understand the experimental results, the degree of aggregation, degradation or distortion of molecular structure upon immobilization.

In this work, three categories of dyes were used (i) monocarboxylic mono-functional, (denoted as dye A) (ii) bi-carboxylic bi-functional (denoted as dye $B$ and dye $C$ ) and (iii) bi-carboxylic mono-functional, denoted as dye $\mathrm{D}$ and dye $E$. The effect of the linkers on the spectral properties is also studied by using two different linkers, (i) 3-aminopropyl- triethoxysilane (APTES) and (ii) branched polyetheleneimine (PEI). The spectra of the dyes are simulated using DFT and TDDFT. The combination of theoretical and experimental observations helps us to identify the effects of the covalent bond formation as well as the mode of immobilization on the spectral properties of the carboxylate dyes and the possibility of aggregation and degradation upon immobilization. This study would help design sensors with bi-functional dyes. While the effect of the solution environment [26] and absorption on solid surface $[27,28]$ have been well studied, most of the work have been based only on experiments, and does not discuss the effect of change of linker molecules in case of covalent attachment of dyes. In this work we have combined theoretical calculations and experimental observations to understand the effects of immobilization on spectral properties of dyes and the shifts due to formation of aggregates. We have also observed the effects of linker molecules by experimentally attaching the given dyes to the surface using different linkers as well as performing theoretical calculations on the attached dye structures. We are not aware of any such studies for acridinediones derivatives, the family of dyes used here, utilising both APTES and PEI as linker for the purpose of immobilization. Also determination of theoretical spectra of given dyes containing more than one dye molecule in immobilized and comparing them with theoretical calculations determining the effect of intermolecular interactions of dyes on spectra, to the best of our knowledge has not been undertaken thus far.

\section{Materials}

N-type Si wafers of (100) orientation with resistivity of 1-20 $\Omega \mathrm{cm}$ were obtained from Silicon Materials, USA. Ammonia solution $25 \%$, hydrochloric acid $37 \%$, hydrogen peroxide $30 \%$, toluene $99 \%$, sulphuric acid $98 \%$ were obtained from Qualigens Fine Chemicals, India, absolute ethanol 99.9\% from S.D. Fine-Chem Ltd, India. DMSO was obtained from Merck Pvt. Ltd, APTES $99 \%$ and PEI with a number average molecular weight $\left(M_{n}\right)$ of 60,000 were obtained from Sigma-Aldrich Inc, Germany, de-ionized (DI) water $(0-0.5 \mathrm{~S} / \mathrm{m})$ from Glen RO+ Systems and zero grade nitrogen from Sigma Gases and Services, India.

Figure 1a(i) provides the schematic of the structure of dye A [4-(3,3,6,6,10-Pentamethyl-1,8-dioxo-1,2,3,4,5,6,7,8,9,10decahydro-acridin-9-yl)-benzoic acid] which has one carboxylic group capable of reacting with amine terminated surface. Figure $1 \mathrm{a}$ (ii) provides the schematic of the structure of dye B [4-[9-(4-Hydroxy-phenyl)-3,3,6,6-tetramethyl-1,8-dioxo-2,3,4,5,6,7,8,9-octahydro-1H-acridin-10-yl]-benzoic acid] which has two carboxylic groups attached to phenyl rings, where one of the phenyl rings is attached to a nitrogen atom while other is attached to a carbon atom. Figure 1 a(iii) provides the schematic structure of dye C[4-[10-(3-Carboxypropyl)-3,3,6,6-tetramethyl-1,8-dioxo-1,2,3,4,5,6,7,8,9,10decahydro-acridin-9-yl]-benzoic acid] which also has two carboxylic groups, one of which is attached to a phenyl ring while the other is attached to an aliphatic chain consisting of three carbons. Figure $1 \mathrm{a}$ (iv), (v) provides the schematic of the structures of dye D[4-[9-(4-Hydroxy-phenyl)-3,3-dimethyl1,8-dioxo-2,3,4,5,6,7,8,9-octahydro-1H-acridin-10-yl]-butyric acid] and dye $E$ [4-[9-(4-Hydroxy-phenyl)-3,3,6,6-tetramethyl1,8-dioxo-2,3,4,5,6,7,8,9-octahydro-1H-acridin-10-yl]-benzoic acid] respectively, both these dyes have one carboxylic group; in case of the former it is attached to an aliphatic chain consisting of 3 carbon atoms, and in case of the later it is attached to a phenyl ring. The procedure of synthesis of the dyes is given by Thorat et al. [29]. Figure $1 b(i)$, (ii) are schematic (two dimensional) representation of the parts of dye molecule which were used to obtain dihedral angle and bond angle data are using Gaussview5 software.

\section{Methods}

\subsection{Immobilisation of dyes to surface}

The schematics of the attachment by both covalent (using two different linkers) and non-covalent routes are shown in Fig. 2. Non-covalent route was used to check the possibility of physisorption. DMSO was used as the solvent for preparing the dye solution, and the solution 


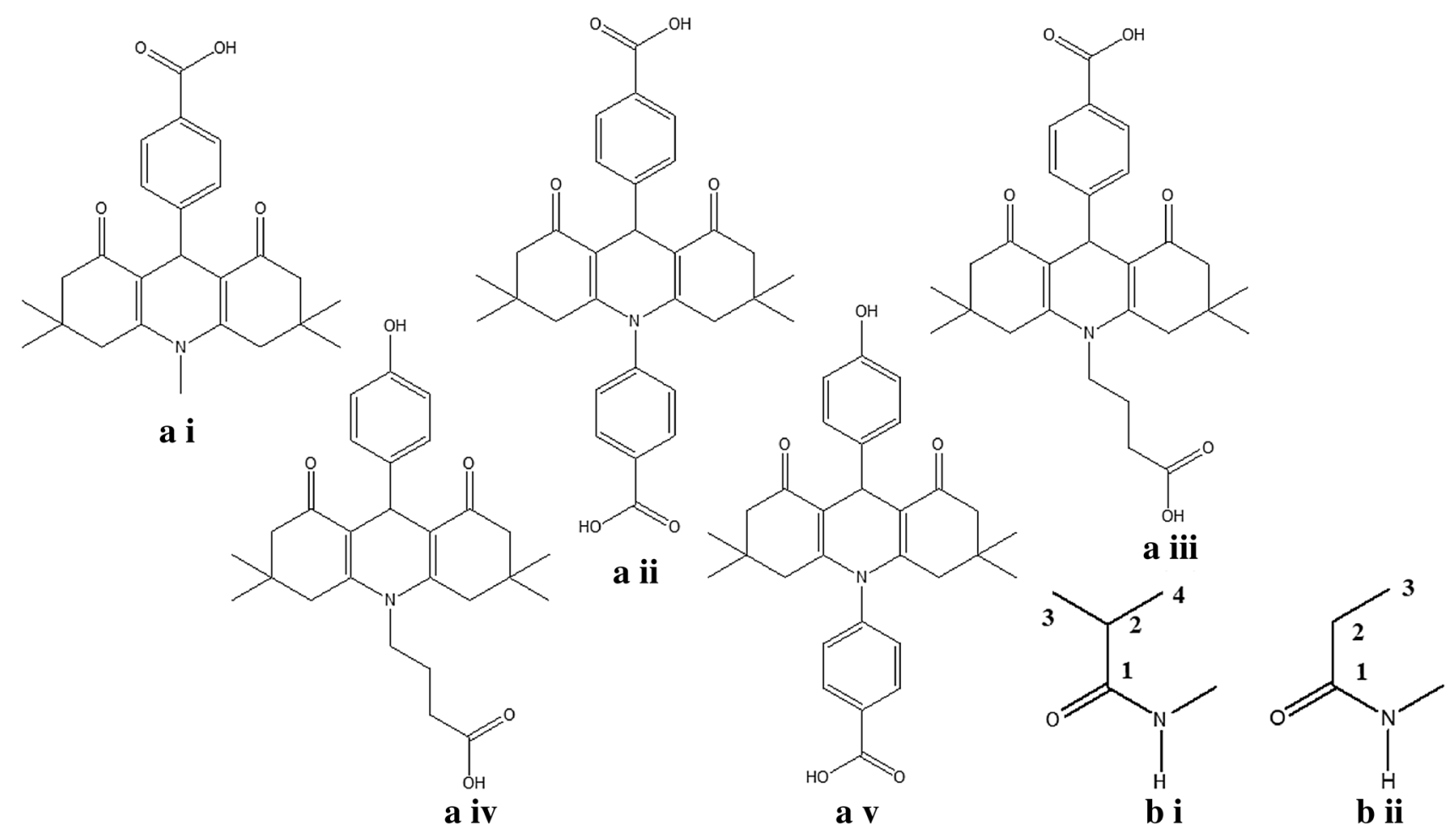

Fig. 1 a Molecular structure of the dyes used. (i) dye A (ii) dye B (iii) dye C (iv) dye D (v) dye E. b Nomenclature system for terminal carboxyl group attached to (i) aromatic carbon (ii) aliphatic carbon

was activated by NHS and then by EDC, where the proportion of dye: NHS: EDC was 1:1.5:2. The dye concentration in the solution was $500 \mathrm{ppm}$. Higher concentration was used to facilitate higher degree of immobilization of dye molecules on the surface. For attachment, the wafers were cleaned and hydrolyzed with piranha solution [30]. Then some wafers were coated with PEl and some with APTES [31], and the rest were kept in the hydrolyzed condition. Then the wafers were dipped in the activated dye solution for $24 \mathrm{~h}$ and subsequently washed with DMSO and dried under nitrogen.

\subsection{Characterisation}

For the spectra of dyes in solution (with absolute ethanol), $10 \mathrm{ppm}$ dye solutions were prepared in DMSO and were characterised by a UV-Vis spectrophotometer (LAMBDA 750 from Perkin Elmer), in the transmission mode with a scan range of $200-800 \mathrm{~nm}$. The spectra of the immobilised samples (non-transparent) were determined by UV-Vis spectrophotometer (Varian 5000 from Agilent) in the reflectance mode, with the scan range $200-800 \mathrm{~nm}$ with a scan rate of $600 \mathrm{~nm} / \mathrm{min}$ at a full slit height.

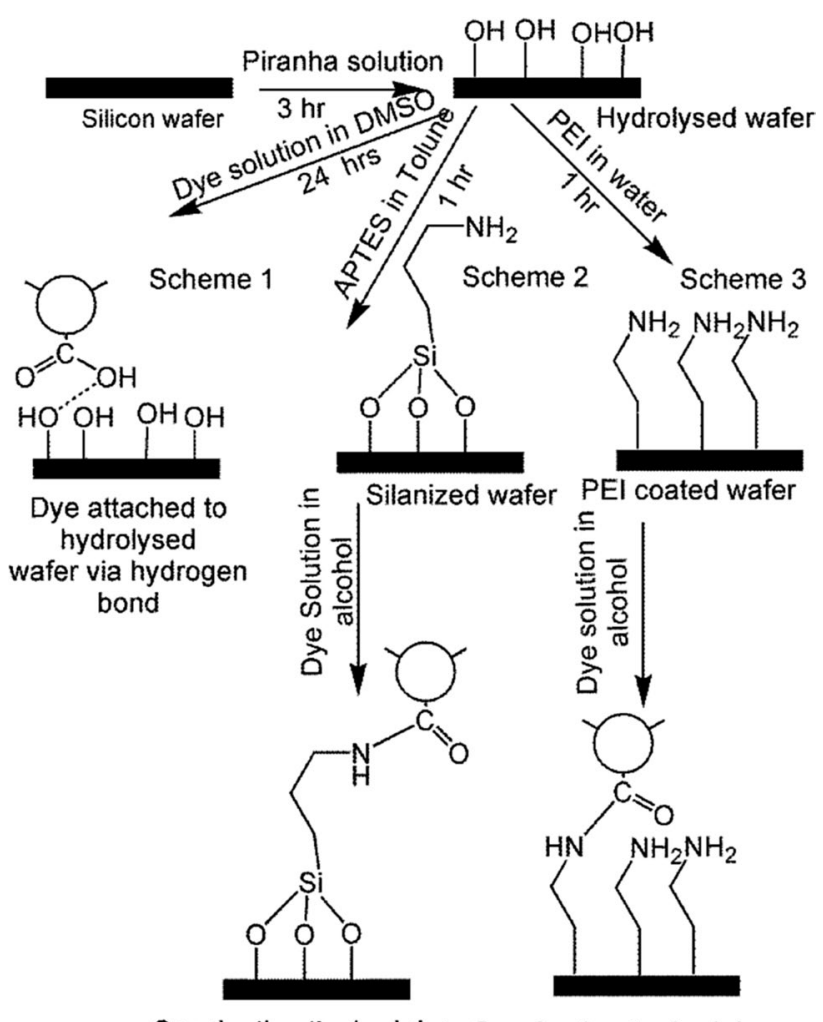

Covalently attached dye Covalently attached dye

Fig. 2 Scheme of immobilization of dyes 


\subsection{Theoretical calculations}

Absorption spectra of the dyes were computed using DFT and TDDFT [22-25, 32] with the global hybrid functional B3LYP [33] and the coulomb-attenuated-method (CAMB3LYP). The basis sets $6-31 \mathrm{G}(\mathrm{d})$ and $6-31 \mathrm{G}(\mathrm{d}, \mathrm{p})$ were used for all the atoms. The fluid atmosphere was created using the CPCM model [34] and calculations were done using Gaussian 09 [35]. The dye molecules, the linkers and the silicon chains were drawn using Avogadro [36]. The silicon structure is approximated by four silicon atoms connected by single bonds in a tetrahedral geometry, the rest of the valences of the terminal silicon atoms are satisfied by hydrogen atoms. The PEI chain is approximated with an oligomer consisting of one primary, two secondary and one tertiary amine group. For the study of interaction of two dyes two units of tetrahedral assembly of silicon atoms and two units of PEl oligomer, as described above, is used. For all the structures, yellow spheres depict silicon, light blue depicts carbon, deep blue-nitrogen, red-oxygen and white depicts hydrogen atoms, the solid lines depict covalent bonds whereas the dotted line depicts the hydrogen bonds. The dihedral angles, bond angles and bond lengths data were extracted from the optimized files using GaussView5 package.

\section{Results and discussions}

As mentioned in Sect. 2, three categories of dyes are studied here (Fig. 1). Dye A with only one carboxylic group is considered as the control dye. The spectral properties of dye $A$, in solution and in immobilised state, are discussed in Sect. 4.2. The spectral properties of dye $B$ and dye $C$ are discussed in Sect. 4.3 and that of dye $D$ and dye $E$ are discussed in Sect. 4.4. All these different combinations would help understand the role of the linkers in determining the spectral properties upon adsorption. The non-covalent attachment method showed no retention of dyes on surface upon immobilization. Hence, in the subsequent sections we discuss only the covalently immobilized molecules.

\subsection{Validation of theoretical calculations}

A stepwise approach was taken for predicting the absorption spectra of the dyes. Initially B3LYP hybrid function was chosen on the basis of its agreement with experimentally observed values [37] to predict the spectra of the dyes in solution. The DFT calculations were done using B3LYP hybrid functional, using the basis sets $6-31 \mathrm{G}(\mathrm{d})$ and $6-31 G(d, p)$. The output files of the DFT calculations were then used as the input files for the TDDFT calculations which provided the theoretical absorption spectra. The calculated values of the maxima of the absorption peaks $\left(\lambda_{\max }\right)$ obtained using both basis sets differed with the experimentally observed values of the maxima of the absorption peaks by $60 \mathrm{~nm}$. To obtain results close to the experimental value, we shifted to the CAM-B3LYP hybrid functional [38-41] with 6-31G(d) basis set. The shift in theoretically obtained $\lambda_{\max }$ values from the experimentally observed values, were lesser for CAM-B3LYP compared to those using B3LYP for both the $6-31 \mathrm{G}(\mathrm{d})$ and the $6-31 G(d, p)$ basis sets. After determining the optimal density functional, we obtained theoretical spectra of all the dyes using higher basis sets $([6-311+G(d, p)]$ and $[6-311++G(d, p)])$ the values, thus obtained were shifted more towards longer wavelength compared to those obtained using 6-31G(d) This prompted us to use CAMB3LYP with the basis set 6-31G(d) for further calculations involving attached molecules.

Table 1 lists the theoretically calculated values (of the maxima of the absorption peaks) along with the experimentally obtained values, the experimental spectra of the dyes in the solution showed only a single peak and no aggregate formation was observed in this case. The difference in value of $\lambda_{\max }$ between the experimental values and theoretically calculated values using CAM-B3LYP hybrid function was within $20 \mathrm{~nm}$, and these values are in good agreement with the literature $[42,43]$.
Table 1 Theoretical and experimental $\lambda_{\max }$ values for absorption spectra of dyes

\begin{tabular}{|c|c|c|c|c|c|c|c|}
\hline \multirow[t]{3}{*}{ Dye } & \multirow{3}{*}{$\begin{array}{l}\text { Experimen- } \\
\text { tal } \lambda_{\max } \\
(\mathrm{nm})\end{array}$} & \multicolumn{6}{|c|}{ Theoretical $\lambda_{\max }(\mathrm{nm})$} \\
\hline & & \multicolumn{2}{|l|}{ B3LYP } & \multicolumn{4}{|l|}{ CAM-B3LYP } \\
\hline & & {$[6-31 G(d)]$} & {$[6-31 \mathrm{G}(\mathrm{d}, \mathrm{p})]$} & {$[6-31 G(d)]$} & {$[6-31 \mathrm{G}(\mathrm{d}, \mathrm{p})]$} & {$[6-311+G(d, p)]$} & $\begin{array}{l}{[6-} \\
311++G(d, p)]\end{array}$ \\
\hline A & 381 & 439 & 440.7 & 401 & 403 & 411 & 411 \\
\hline B & 385 & 435 & 435.5 & 394.6 & 395 & 405 & 405 \\
\hline C & 384 & 442 & 444 & 402 & 404 & 413 & 413 \\
\hline D & 384 & 433 & 434 & 399.2 & 400 & 410 & 410 \\
\hline $\mathrm{E}$ & 372 & 389 & 389 & 382 & 383 & 402 & 402 \\
\hline
\end{tabular}


Once the appropriate hybrid functional was obtained by comparing theoretical and experimental results of free dye molecules in solution, attached dye molecules (described in Sect. 3.3) were subjected to theoretical calculations. The results are described in subsequent sections.

\subsection{Spectra of the mono-carboxylic mono-functional dye}

The structures and the absorption spectra for dye $\mathrm{A}$ are given in Fig. 3. Figure 3a(i) showed that the dye molecule attached to a APTES linker which in-turn is attached to the surface via a $\mathrm{Si}-\mathrm{O}-\mathrm{Si}$ bond and Fig. 3a(ii) represents the dye attached via PEI to the surface, these are depicted as no-interacting structures. Figure $3 a$ (iii) shows two dye $\mathrm{A}$ molecules attached via APTES linker to the surface and Fig. 3a(iv) presents the same using PEI as the linker, these two are considered as interacting structures. Figure $3(b)$ represents the absorption spectra (theoretical and experimental) of dye A. Figure $3(\mathrm{~b})$ presents the absorption spectra (theoretical and experimental) of dye A; Fig. 3b(i) presents the theoretical spectra of the non-interacting dye molecule with both the linkers, APTES and PEI, (i.e. involving one dye molecule and one linker molecule) and the experimental spectra involving both the linkers, Fig. $3 b$ (ii) presents theoretical spectra of interacting (involving two dye molecules in close proximity) and non-interacting dye molecules with APTES linker and the experimental spectra of attached dye molecules with APTES linker, Fig. $3 \mathrm{~b}$ (iii) presents the theoretical spectra of interacting and non-interacting dye molecules with PEl linker and the experimental spectra of the dye molecules attached via PEI linker. The effect(s) of the linkers by comparing the theoretical spectra and experimental spectra can be observed from Fig. $3 b$ (ii), (iii). Both the linkers provided sufficient moieties in between the surface and the dye to prevent the possibility of surface to dye charge transfer. Once the carboxyl group formed an amide bond with the amine terminated surface, there is no possibility of further attachment with the dye, and hence it is chosen as the control dye. The hydroxylated surfaces kept in the dye solution did not show any characteristic peak suggesting there was no retention of dyes when there was no covalent bonding between the dyes and the groups which are on the surface. The calculated spectra in solution for dye A showed a peak at $401 \mathrm{~nm}, 20 \mathrm{~nm}$ more than that calculated for the dye in solution. Theoretically calculated values of $\lambda_{\max }$ which lie on both the higher and the lower side of experimentally observed values of $\lambda_{\max }$ have been reported in literature depending on the structure of the dyes and the solvent used [44, 45]. The hybrid function as well as the fluid model determines to what extent the theoretical values will match with that of the experimental values. The difference between the theoretically calculated absorption maxima and experimentally obtained absorption maxima are within the limits reported in literature [43-45].

Table 2 presents the theoretically calculated and the experimentally observed values of $\lambda_{\max }$ for dye $A$, both in the solution and in the immobilised state. Upon immobilisation, we observed a blue shift in the theoretical absorption spectra with both the linkers, which indicates that the gap between the energy levels increases upon immobilisation. This further implies some other factor(s) play(s) a role apart from the covalent attachment. Figure $3 b$ (i) depicts the spectra of immobilized dye molecules, both the theoretically calculated and the experimentally obtained ones. The experimental spectra have different distinct peaks, of which the peaks around $460 \mathrm{~nm}$ are of interest. Both the linkers, APTES and PEI, contain aliphatic amines. For APTES the nature of the aliphatic amine is primary whereas PEI contains primary, secondary as well as tertiary aliphatic amine groups. Some of these groups react with the dye molecules while others remain free, and the peak in the experimental spectra in the range of $320-325 \mathrm{~nm}$ is attributed to these free aliphatic amine groups. The peaks observed in both the experimental spectra in the range of 320-325 nm, arises due to aliphatic amine, present in the linkers, which is also reported by Kumar et al. [46]. The peak around $230-240 \mathrm{~nm}$ could be due paramagnetic defects on silicon surface as reported by Rahman et al. [47] and Kumar et al. [46]. To determine whether presence of another dye molecule in the neighbourhood affects the spectra, theoretical calculations were carried out with two immobilized dye molecules in close proximity, for both the linkers. The structures used for theoretical calculations is described in Sect. 3.3.

There are conflicting results reported in literature regarding the nature and magnitude of the shift in the absorption peaks from solution to the immobilised state. Some authors $[48,49]$ reported about $50 \mathrm{~nm}$ of blue shift upon immobilization while others $[5,50]$ have reported simultaneous red and blue shift upon immobilisation. The experimental spectra for the solution and the immobilised state in this work showed a red shift and this is in contradiction with the expectation from the theoretical results. Dyes immobilised to metal surfaces show red shift upon immobilisation due to metal-dye charge transfer, but introduction of a linker negates that effect [51]. In this study the presence of the linker to attach the dye to the substrate rules out the possibility of such a charge transfer. This implies some other factors are stabilising the energy levels. A possible explanation of this could be that the carboxyl group is an acceptor group in the donor-acceptor chromophore we have used, with the donor being the nitrogen atom (which contains a lone pair of electrons). During immobilisation, there is a covalent bond between 

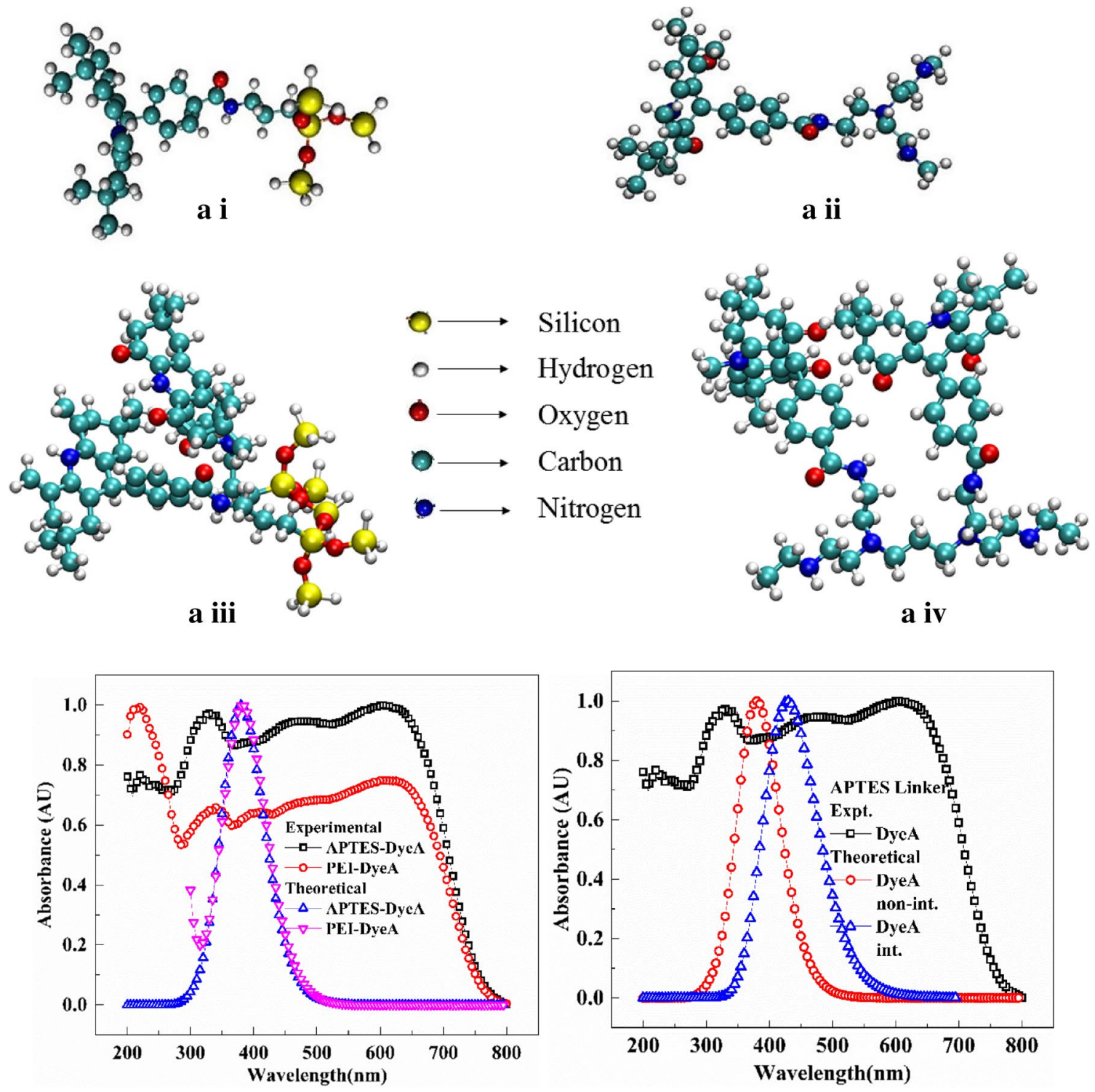

b i

b ii

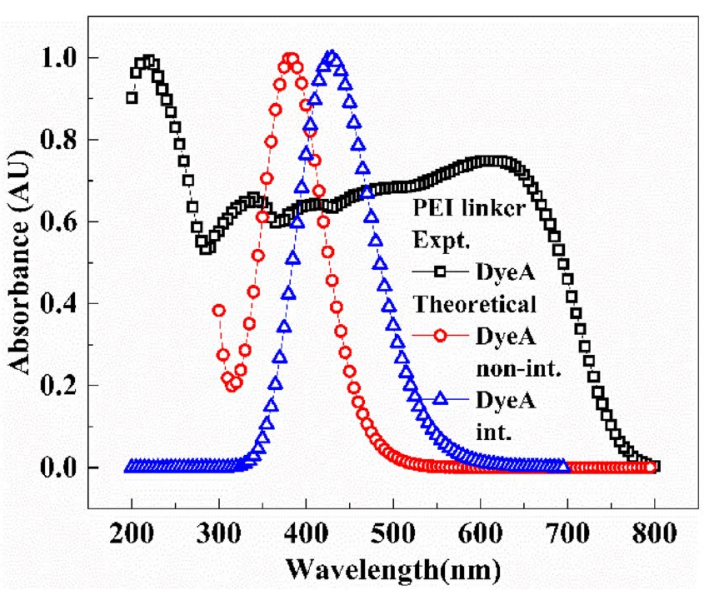

b iii 
4 Fig. 3 a CPK model structure of dye A for theoretical calculations (a) attached using (i) APTES- (ii) PEl. b Spectra of dye A in the immobilised state involving experimental and theoretical spectra of (i) non-interacting dye molecule with both linkers (ii) interacting and non-interacting dye molecules with APTES linker (iii) interacting and non-interacting dye molecules with PEI linker

the dye and the surface, and therefore the nature of the carboxy group is modified-it becomes a stronger acceptor. It is known that in a Donor-Acceptor chromophore, increasing donor as well as acceptor capacity would lead to a red shift and this is what has happened here.

The double humped peak in the experimental spectra indicates that aggregate formation has taken place as similar phenomenon has been reported by other authors $[5,50,52]$. The dihedral and bond angle values were extracted from the optimized structures. The purpose of this exercise is to determine whether the dye structure is distorted upon attachment or not. If the dihedral angle and bond angle values differ significantly from normal values, expected from the nature and hybridized state of atoms involved, then there is a possibility that there might be degradation of the dye structure upon attachment. The 2D representation of the moieties, from which the data was extracted, are shown in Fig. $1 \mathrm{~b}$ (i), (ii). The theoretically calculated dihedral angle $\mathrm{a}\left(\mathrm{O}=\mathrm{C}_{1}-\mathrm{C}_{2}-\mathrm{C}_{4}\right)$ is $179^{\circ}$ where as that of the immobilized dye using silane and PEI are $156^{\circ}$ and $158^{\circ}$ respectively. This closeness of the values indicated that nature of the linkers used here affect the covalent bond formation in a similar manner. This fact is also observed while calculating the bond angle of $\angle O=C_{1}-C_{2}$, where the value is $121.4^{\circ}$ for the free molecule, while immobilized molecules had values of $122.4^{\circ}$ and $121.5^{\circ}$ using silane and PEI as the linker, respectively. The values are close to what is expected from a double bonded carbon atom $\left(120^{\circ}\right)$. The theoretical absorption spectra also showed that the linker molecules affected the spectra in a similar manner as indicated by the dihedral angle and the bond angle values of the free and the immobilized molecules. The theoretical calculations indicated blue-shift in the absorption maxima while the experimentally observed results showed a large red shift. This contradiction in the results can be explained by incorporating the effect of neighbouring molecules in the theoretical calculations. Theoretical calculations involving covalent bond formations between the amine terminated surface and a single dye molecule (Fig. 3a(i), (ii)) did not capture the effect of the interaction between the dye molecules in close proximity. To overcome this shortcoming, theoretical calculations involving two attached dye molecules in proximity were carried out (Fig. 3a(iii), (iv)). The $\lambda_{\max }$ values obtained from such calculations with APTES as the linker was found to be $428 \mathrm{~nm}$ and that with PEI as linker was
$431 \mathrm{~nm}$. The values obtained from these calculations of two immobilized molecules in proximity were found to be closer to the experimental values compared to that obtained from calculations of a single immobilized molecule. The dye-dye interactions could have stabilized the ground states thereby resulting in the red shift. This shows that dye-dye interaction affects the spectra and theoretical calculations involving single immobilized molecules were not able to capture this effect. Due to limitations of available facilities we could not go beyond two molecules, never the less these calculations contributed in strengthening our conjecture that dye-dye interaction caused the large red shifts obtained in experimental spectra of immobilized dyes. The interaction study was carried out only with dye $A$ as single dye molecule systems followed the same trend it was expected two molecule system will do the same.

\subsection{Bi-carboxylic Bi-functional dyes}

Dye $B$ and dye $C$ are bi-functional dyes with two carboxylic moieties available for attachment. The structures of the dyes used for theoretical calculations and the absorption spectra (both theoretically calculated and experimentally obtained) are shown in Figs. 4 and 5 respectively.

Figure $4 a(i)$, (ii) represents the structure of dye $B$ attached to APTES via two different carboxylic groups which are at two ends of the dye molecule (details are provided in Sect. 2). Figure 4a(iii), (iv) represent the structure of dye $B$ attached to the amino group of PEI via two different carboxylic groups. The different regions of connectivity were chosen to investigate whether or not there is an extended conjugation with the linker. Since the carboxylic groups are different, any extended conjugation with the linkers will affect the spectra differently. Figure 4(b) presents the combined spectra of all the theoretical and experimental findings. The $\lambda_{\max }$ values are given in Table 3 .

Figure $5 a(i)$, (ii) represent the structure of dye $C$ attached to APTES by two different carboxylic groups. Figure $5 \mathrm{a}(\mathrm{iii})$, (iv) represent the structure of dye $C$ attached to the amino group of PEI via two different carboxylic groups. Figure $5(b)$ represents the combined absorption spectra of the theoretical and the experimental findings. Table 3 presents the $\lambda_{\max }$ values of the theoretical and the experimental spectra for dye $B$ and dye $C$, both for solution and immobilised state. Theoretical calculations of the $\lambda_{\max }$ values for dye $B$ show that when the dye is attached to a linker via two different carboxylic groups (denoted as the $\mathrm{C}$ end and the $\mathrm{N}$ end), the $\lambda_{\max }$ values are quite close ( $380 \mathrm{~nm}$ and $381 \mathrm{~nm}$ for APTES). This is true for PEl as well (381 nm and $383 \mathrm{~nm}$ ). Theoretical calculations for dye C also yields similar results. This leads us to believe that covalent bonding of the terminal carboxylic group does not 
Table 2 Theoretical and experimental $\lambda_{\max }$ values of absorption spectra for dye $\mathrm{A}$

\section{Dye Experimental $\lambda_{\max }$ in solution $(\mathrm{nm})$}

Experimental $\lambda_{\max }$ in immobilised state $(\mathrm{nm})$
Theoretical $\lambda_{\max }$ in Theoretical immobilised state $\lambda_{\max }$ in immofor non-interact- $\quad$ bilised state ing system $(\mathrm{nm}) \quad$ for interacting system $(\mathrm{nm})$

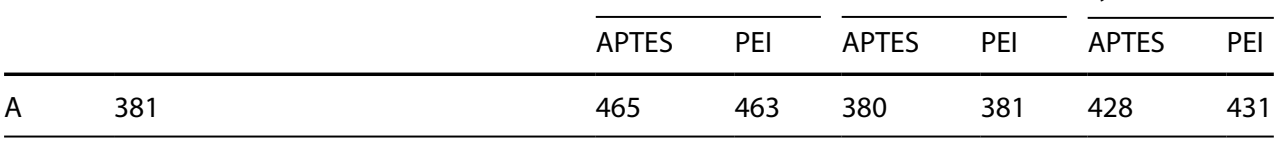

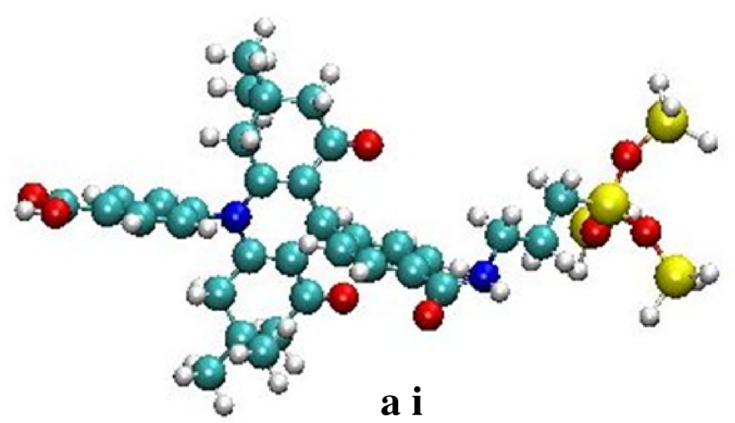

$\mathbf{a} \mathbf{i}$

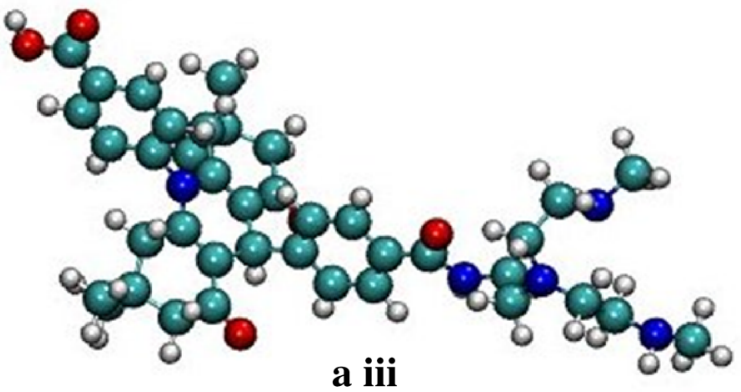

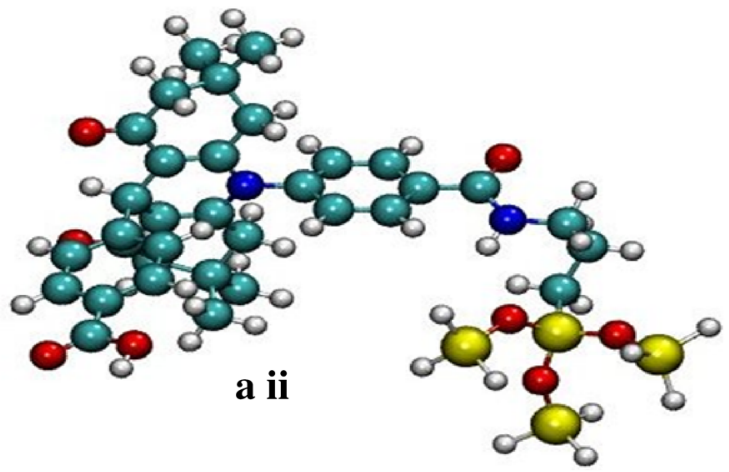

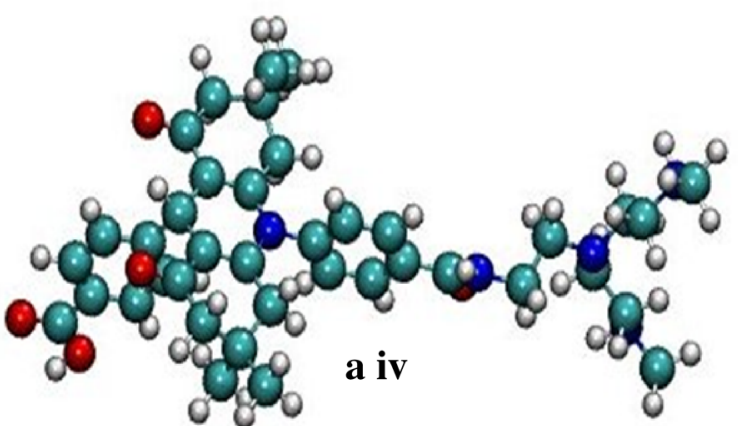

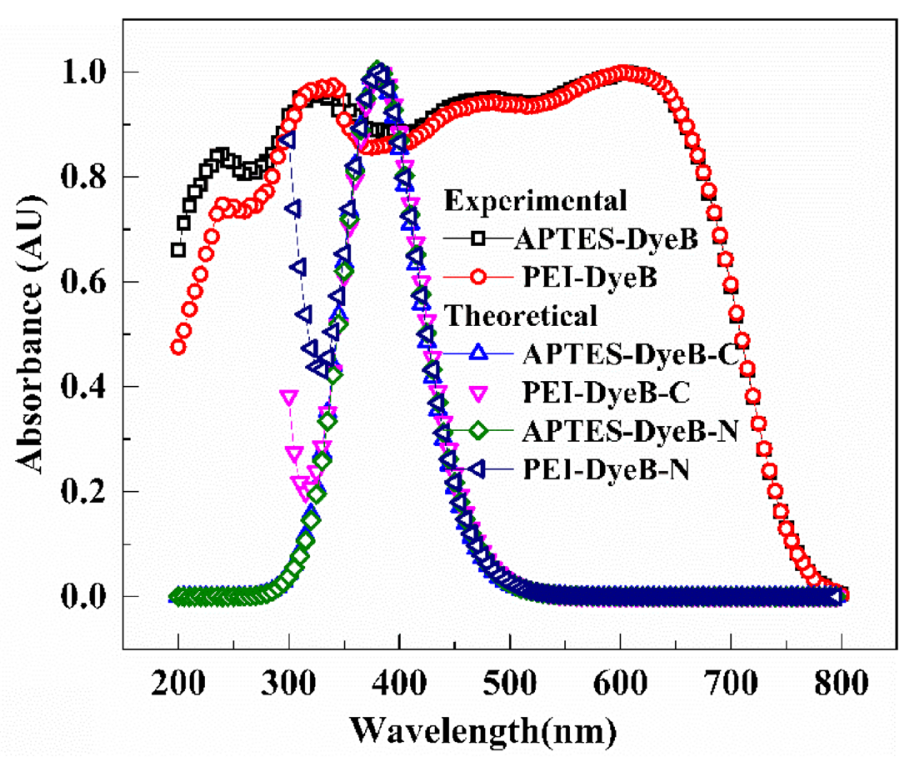

b

Fig. 4 CPK model structure of dye B for theoretical calculations a attached using (i, ii) APTES via two distinct carboxylic groups (iii, iv) PEl via two distinct carboxylic groups. b Theoretical and experimental spectra of dye B in the immobilised state 


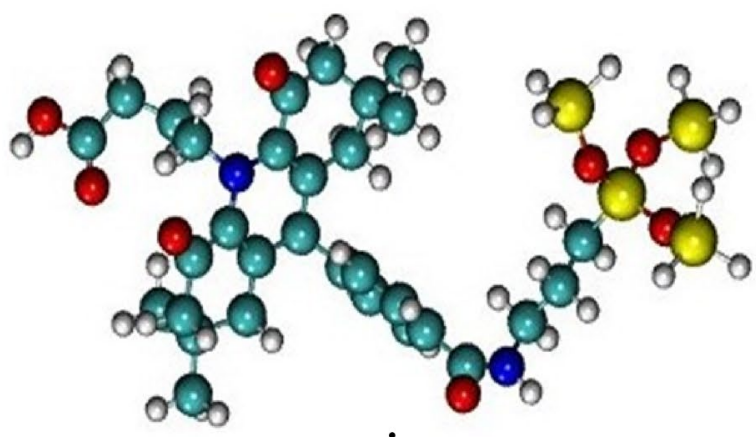

$\mathbf{a} \mathbf{i}$

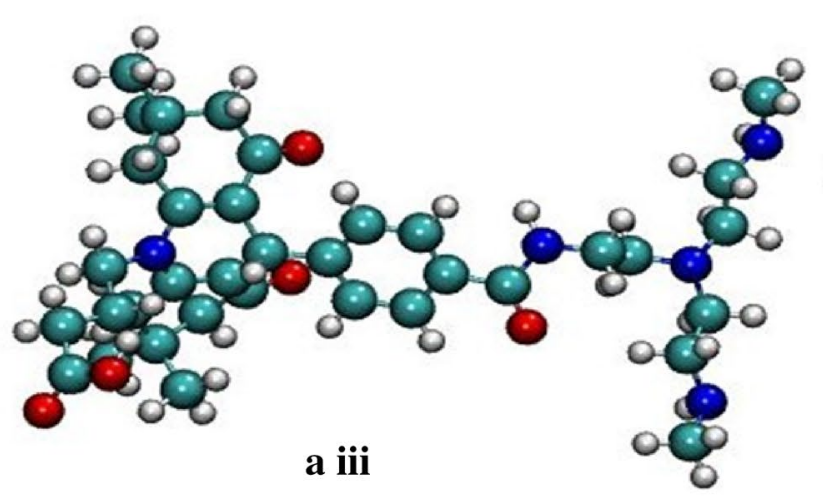

a iii

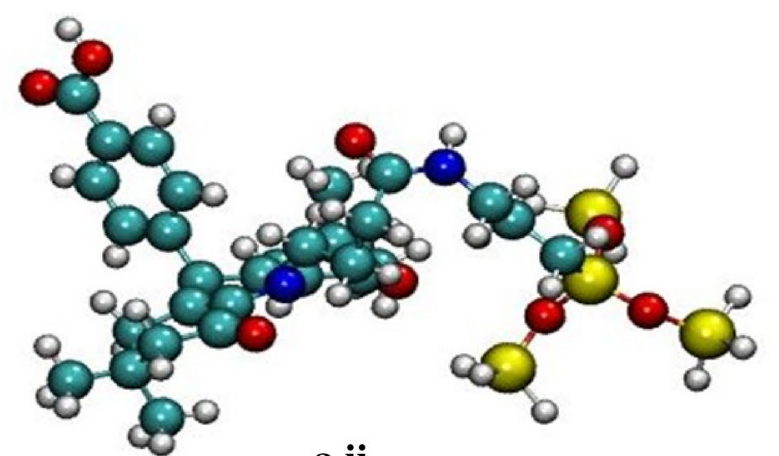

a ii

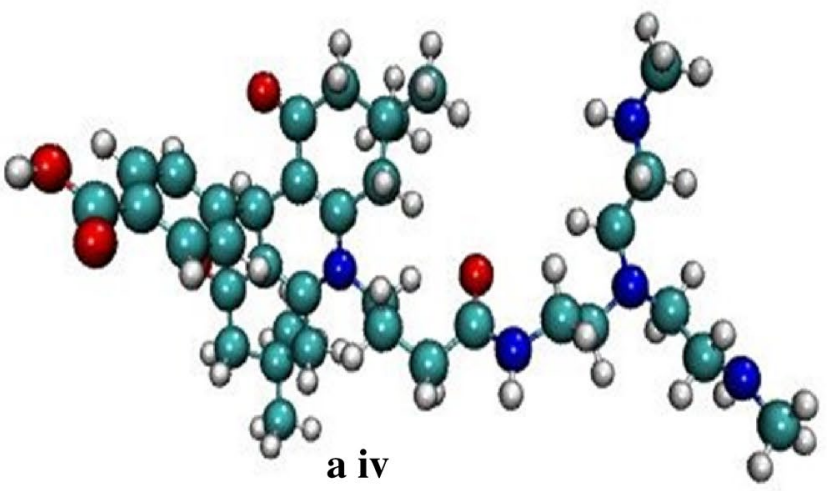

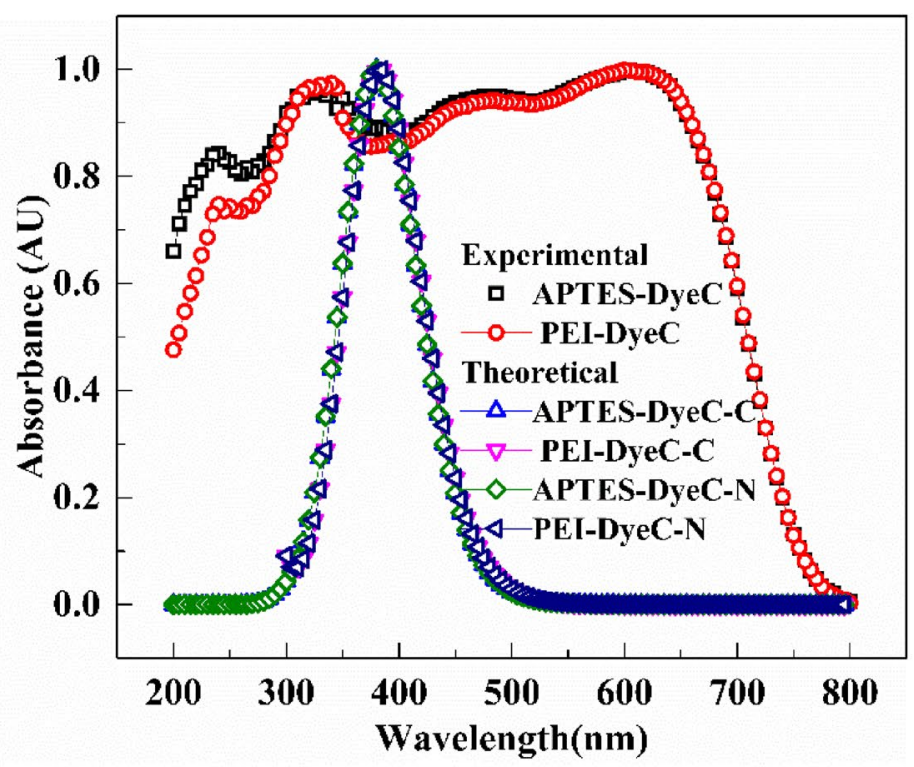

b

Fig. 5 Attached CPK model structure of dye C for theoretical calculations a (i, ii) APTES via two distinct carboxylic groups (iii, iv) PEI via two distinct carboxylic groups $\mathbf{b}$ Theoretical and experimental spectra of dye $\mathrm{C}$ in the immobilised state

affect the conjugation to a large degree. These dyes also show a blue shift upon immobilisation in the theoretically simulated spectra while experimental spectra on the other hand show a large red shift as was the case with dye $A$. The $\lambda_{\max }$ value considered here are $470 \mathrm{~nm}$ for APTES as linker and $466 \mathrm{~nm}$ for PEl as linker. The origin of the rest of the peaks are explained in Sect. 4.2. Considering that the theoretical spectra indicates that only covalent bond formation does not cause such magnitude of red shift in absorption maxima, a possible reason is formation of aggregates [28] which was indicated in the case of dye A. Formation of such aggregates upon immobilization of carboxylate dyes 
Table 3 Theoretical and experimental $\lambda_{\max }$ values of absorption spectra for dye $B$ and $C$

\begin{tabular}{|c|c|c|c|c|c|}
\hline \multirow[t]{2}{*}{ Dye } & \multirow[t]{2}{*}{$\begin{array}{l}\text { Experimental } \lambda_{\max } \\
\text { in solution }(\mathrm{nm})\end{array}$} & \multicolumn{2}{|c|}{$\begin{array}{l}\text { Experimental } \\
\lambda_{\max } \text { in immo- } \\
\text { bilised state } \\
(\mathrm{nm})\end{array}$} & \multicolumn{2}{|c|}{$\begin{array}{l}\text { Theoretical } \\
\lambda_{\max } \text { in immo } \\
\text { bilised state } \\
(\mathrm{nm})\end{array}$} \\
\hline & & APTES & PEI & APTES & PEI \\
\hline B-carbon end & 385 & 470 & 466 & 380 & 381 \\
\hline B-nitrogen end & & & & 381 & 382 \\
\hline C-carbon end & 384 & 468 & 471 & 380 & 383 \\
\hline C-nitrogen end & & & & 381 & 382 \\
\hline
\end{tabular}

on different surfaces has been reported by Mulhern et al. [28] and Choi et al. [53]. So formation of aggregates on the surface in our case is not an exception. The red shift (bathochromic shift) indicates formation of J-aggregates.

To further strengthen our hypothesis, two different bi-functional mono carboxylic dyes were subjected to investigation.

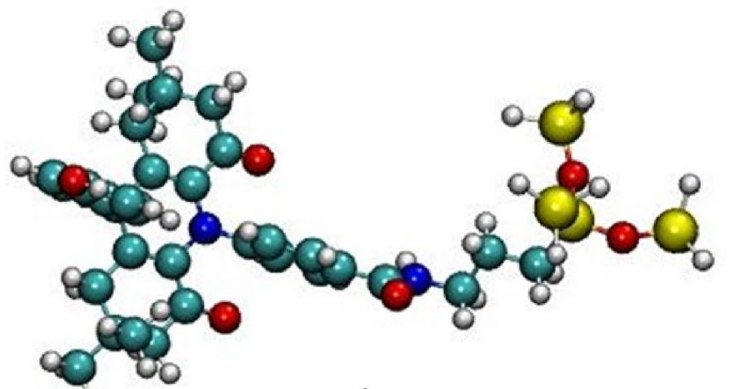

$\mathbf{a} \mathbf{i}$

\subsection{Bi-functional mono carboxylic dyes}

Dye $\mathrm{D}$ and dye $\mathrm{E}$ are bi-functional dyes but they have only one carboxylic group to connect with the linker. The $-\mathrm{OH}$ groups present can form hydrogen bond with the neighbouring molecule and aid in aggregate formation. The structures used for theoretical calculations and the absorption spectra are shown in Figs. 6 and 7 respectively.

Figure $6 \mathrm{a}(\mathrm{i})$ or $7 \mathrm{a}$ (i) shows the dye structure attached to the surface via a silane linker. Figure $6 a(i i)$ or $7 a(i i)$ shows the dye structure attached via PEI to the surface. Figure $6 \mathrm{~b}$ or $7 \mathrm{~b}$ represents the combined theoretical and experimental spectra of dye D/dye E. Table 4 shows the values of $\lambda_{\max }$ for theoretical and experimental spectra for dye $D$ and dye $E$ for solvated and immobilised states. The theoretical spectra for dye $D$ show a blue shift on immobilisation as expected from the behaviour of the dyes studied earlier. In the case of the experimentally observed spectra, the expected red shift upon immobilisation is observed, indicating aggregation upon immobilisation had a role to play even when the dyes contained only one carboxylic

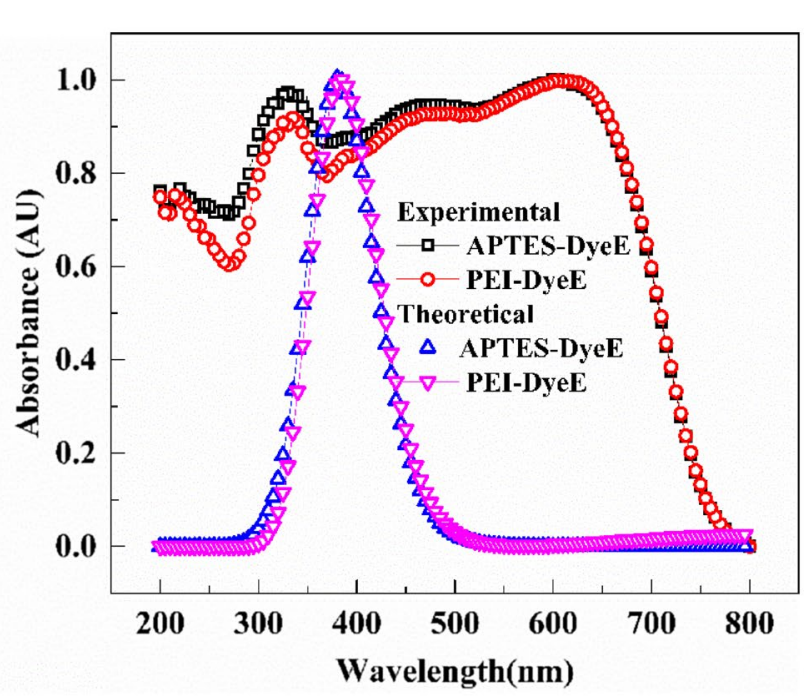

b

Fig. 6 Attached CPK model structure of dye D for theoretical calculations a (i) APTES (ii) PEl. b Theoretical and experimental absorption spectra of dye $D$ in the immobilised state 


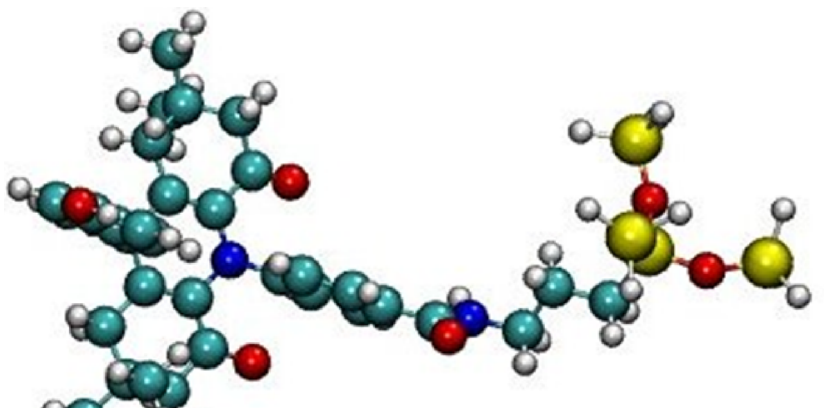

$\mathbf{a} \mathbf{i}$

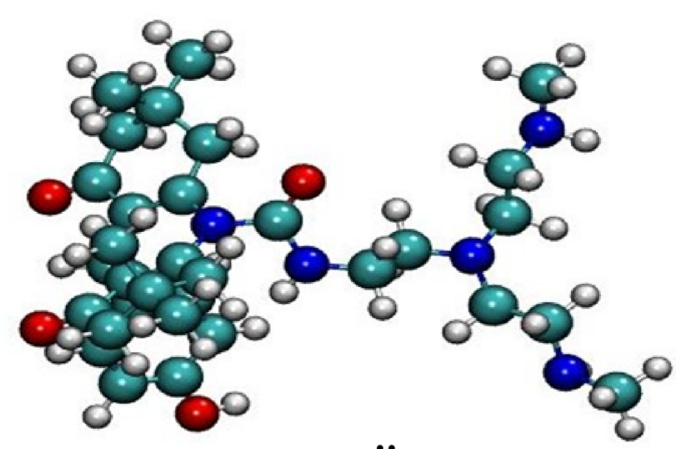

a ii

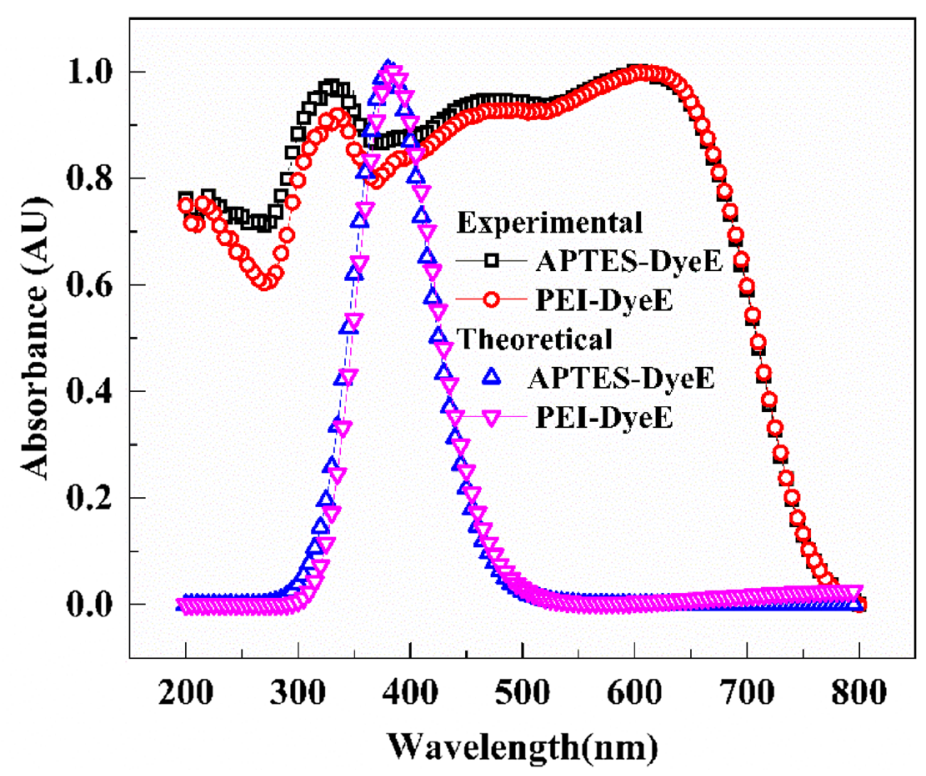

b

Fig. 7 Attached CPK model structure of dye E for theoretical calculations a (i) APTES (ii) PEI. b Theoretical and experimental spectra of dye E in the immobilised state

Table 4 Theoretical and experimental $\lambda_{\max }$ values of absorption spectra for dye $D$ and $E$

\begin{tabular}{|c|c|c|c|c|c|}
\hline \multirow[t]{2}{*}{ Dye } & \multirow[t]{2}{*}{$\begin{array}{l}\text { Experimental } \lambda_{\max } \text { in } \\
\text { solution }(\mathrm{nm})\end{array}$} & \multicolumn{2}{|c|}{$\begin{array}{l}\text { Experimental } \lambda_{\max } \\
\text { in immobilised } \\
\text { state }(\mathrm{nm})\end{array}$} & \multicolumn{2}{|c|}{$\begin{array}{l}\text { Theoretical } \\
\lambda_{\max } \text { in immo- } \\
\text { bilised state } \\
(\mathrm{nm})\end{array}$} \\
\hline & & APTES & PEI & APTES & PEI \\
\hline D & 384 & 474 & 472 & 383 & 386 \\
\hline$E$ & 372 & 463 & 458 & 379 & 384 \\
\hline
\end{tabular}

group. The $-\mathrm{OH}$ groups in this case might have helped in aggregate formation via hydrogen bonding.

The results for all the dyes reveal that the degree of red shift is comparable. As the value of $\lambda_{\max }$ for the dyes in solution are very close, this observation leads to the conclusion that degradation of dyes did not occur upon immobilisation or was negligible and only aggregation has affected the spectra. Thingna et al. [54] have created silicon assemblies for theoretical calculations, Carciato et al. [55] used the ONIOM approach for the same purpose has been used by but such approach is beyond the scope of this study. A comparison of similar works is provided in Table 5 .

The synthesized knowledge from this study can be utilized to fabricate optical or colorimetric sensors. One carboxyl group can be used immobilise the dye on the surface and with the other carboxyl group we can attach affinity proteins, antibody and use them as optical sensors [56]. 
Table 5 Comparison of results with works from other authors

\begin{tabular}{|c|c|c|c|}
\hline Authors & Surface & Linker & Observation \\
\hline Mark et al. [18] & $\mathrm{TiO}_{2}$ & - & Preferential formation of $\mathrm{H}$-aggregates \\
\hline Alderman et al. [4] & $\mathrm{Si}$ & $\begin{array}{l}\text { Diol ( } 2 \text { to } 11 \text { carbon } \\
\text { chain) }\end{array}$ & Preferential monomer formation \\
\hline Liu et al. [27] & $\mathrm{TiO}_{2}$ & - & Preferential monomer formation \\
\hline Mulhern et al. [28] & $\mathrm{TiO}_{2}$ & - & Preferential aggregate formation \\
\hline Our work & $\mathrm{Si}$ & APTES, PEI & Preferential aggregate formation \\
\hline
\end{tabular}

\section{Conclusions}

We have successfully attached a set of carboxylic dyes upon silanol terminated silicon surface, using two linkers (APTES and PEI). The linkers, though similar in terminal group, were different from each other in structure. This difference in structure, contrary to expectation, caused similar red shift in the absorption maxima of the attached dyes. The spectra of the dyes in solution as well as that attached to the surface were also calculated using DFT and TDDFT. It was found that covalent bond formation was not the reason for causing such a large red-shift in spectra of the dyes. From the theoretically obtained spectra of bifunctional dyes it was indicated that conjugation within the dye was affected to smaller extent by covalent bond formation. The theoretical calculations did not take into account effect of neighbouring molecules. These information and nature of the experimental peaks lead us to conclude that formation of aggregates influenced the real life spectra of the attached dyes and caused a large red shift. Another observation was that hardly any degradation occurred upon immobilisation of the dyes.

Acknowledgements The financial support of the Office of the PSA, Government of India (Grant No. Prn.SA/EDD/Bio/2010(G)) is acknowledged. The authors acknowledge HPC IIT Kanpur for providing the computational facilities. The authors thank Prof. Goutam Deo and Prof. Sri Sivakumar for use of their spectroscopic facilities, and Mr. Avijit Kayal and Dr. Malay Rana for their technical inputs.

\section{Compliance with ethical standards}

Conflict of interest The authors declare that they have no conflict of interest.

\section{References}

1. Heeger AJ (2002) Semiconducting and metallic polymers: the fourth generation of polymeric materials. Synth Met 125(1):23-42

2. Beffa F, Back G (1984) Metal complex dyes for wool and nylon1930 to date. Rev Prog Color 14:33-42

3. Katz HE, Singer KD, Sohn JE, Dirk CW, King LA, Gordon HM (1987) Greatly enhanced second-order nonlinear optical susceptibilities in donor-acceptor organic molecules. J Am Chem Soc 109(21):6561-6563

4. Alderman N, Danos L, Fang L, Grossel MC, Markvart T (2017) Light harvesting in silicon(111) surfaces using covalently attached protoporphyrin IX dyes. Chem Commun 53(89):1212012123. https://doi.org/10.1039/C7CC04767C

5. Ehret A, Stuhl L, Spitler MT (2000) Variation of carboxylatefunctionalized cyanine dyes to produce efficient spectral sensitization of nanocrystalline solar cells. Electrochim Acta 45(28):4553-4557

6. Goddard JM, Hotchkiss JH (2007) Polymer surface modification for the attachment of bioactive compounds. Prog Polym Sci (Oxf) 32(7):698-725. https://doi.org/10.1016/j.progpolyms ci.2007.04.002

7. González-Moreno R, Cook PL, Zegkinoglou I, Liu X, Johnson PS, Yang W, Ruther RE, Hamers RJ, Tena-Zaera R, Himpsel FJ, Ortega JE, Rogero C (2011) Attachment of protoporphyrin dyes to nanostructured Zno surfaces: characterization by near edge X-ray absorption fine structure spectroscopy. J Phys Chem C 115(37):18195-18201

8. Mulhern KR, Orchard A, Watson DF, Detty MR (2012) Influence of surface-attachment functionality on the aggregation, persistence, and electron-transfer reactivity of chalcogenorhodamine dyes on $\mathrm{TiO}_{2}$. Langmuir 28(17):7071-7082

9. Nazeeruddin MK, Humphry-Baker R, Liska P, Grätzel M (2003) Investigation of sensitizer adsorption and the influence of protons on current and voltage of a dye-sensitized nanocrystalline $\mathrm{TiO}_{2}$ solar cell. J Phys Chem B 107(34):8981-8987

10. Nazeeruddin MK, Péchy $P$, Renouard T, Zakeeruddin SM, Humphry-Baker R, Cointe P, Liska P, Cevey L, Costa E, Shklover V, Spiccia L, Deacon GB, Bignozzi CA, Grätzel M (2001) Engineering of efficient panchromatic sensitizers for nanocrystalline $\mathrm{TiO}_{2}$-based solar cells. J Am Chem Soc 123(8):1613-1624

11. Tomioka A, Takeuchi T, Takada K (2012) Selective formation of novel fluorescent aggregates of rhodamine dyes: contribution of surface $\mathrm{SiO}_{2}$ layer and underlying $\mathrm{Si}$ layer. Phys Status Solidi (C) Curr Top Solid State Phys 9(12):2428-2431

12. Baxter JB, Aydil ES (2005) Nanowire-based dye-sensitized solar cells. Appl Phys Lett 86(5):1-3

13. Leschkies KS, Divakar R, Basu J, Enache-Pommer E, Boercker JE, Carter CB, Kortshagen UR, Norris DJ, Aydil ES (2007) Photosensitization of $\mathrm{ZnO}$ nanowires with $\mathrm{CdSe}$ quantum dots for photovoltaic devices. Nano Lett 7(6):1793-1798

14. Olson DC, Lee YJ, White MS, Kopidakis N, Shaheen SE, Ginley DS, Voigt JA, Hsu JWP (2007) Effect of polymer processing on the performance of poly(3-hexylthiophene)/ZnO nanorod photovoltaic devices. J Phys Chem C 111(44):16640-16645

15. Uhlrich JJ, Franking R, Hamers RJ, Kuech TF (2009) Sulfide treatment of $\mathrm{ZnO}$ single crystals and nanorods and the effect on P3HT-ZnO photovoltaic device properties. J Phys Chem C 113(50):21147-21154

16. Willner I, Eichen Y, Frank AJ, Fox MA (1993) Photoinduced electron-transfer processes using organized redox-functionalized 
bipyridinium-polyethylenimine- $\mathrm{TiO}_{2}$ colloids and particulate assemblies. J Phys Chem 97(28):7264-7271

17. Zhang L, Lin S (2019) Effect of novel anchoring groups on the electronic and optical properties of water-splitting metal-free dye molecules: a first-principles investigation. Chem Phys 522:84-90. https://doi.org/10.1016/j.chemphys.2019.02.020

18. Mark MF, Kryman MW, Detty MR, McCamant DW (2018) Intermolecular charge separation in aggregated rhodamine dyes used in solar hydrogen production. J Phys Chem C 122(29):1651916531. https://doi.org/10.1021/acs.jpcc.8b03045

19. Zhang $Y$, Huang G, An C, Xin X, Liu X, Raman M, Yao Y, Wang W, Doble $M$ (2017) Transport of anionic azo dyes from aqueous solution to gemini surfactant-modified wheat bran: synchrotron infrared, molecular interaction and adsorption studies. Sci Total Environ 595:723-732. https://doi.org/10.1016/j.scito tenv.2017.04.031

20. Lim K, Song K, Kang Y, Ko J (2015) Organic sensitizers possessing carbazole donor and indeno[1,2-b] thiophene spacer for efficient dye sensitized solar cells. Dyes Pigm 119:41-48. https:// doi.org/10.1016/j.dyepig.2015.03.013

21. Li J, Wang L, Zhang Q, Wu W, He C, Zhang J (2015) Investigation and design of high efficiency carbazole-based sensitizers for solar cells: effect of the nature and length of $\pi$-linker. Organ Electron Phys Mater Appl 22:108-116. https://doi.org/10.1016/j. orgel.2015.03.038

22. Cossi M, Scalmani G, Rega N, Barone V (2002) New developments in the polarizable continuum model for quantum mechanical and classical calculations on molecules in solution. J Chem Phys 117(1):43-54

23. Tomasi J, Mennucci B, Cammi R (2005) Quantum mechanical continuum solvation models. Chem Rev 105(8):2999-3093

24. Holland JP, Barnard PJ, Bayly SR, Dilworth JR, Green JC (2009) Electronic absorption spectroscopy and time-dependent density functional theory calculations on the nickel(II) complex of 1,4-bis(pyrrol-2-ylmethyleneamino)butane. Inorg Chim Acta 362(2):402-406

25. Tüğsüz T, Sevin F (2006) A DFT study on the structures and absorption spectra of the M-1-nitroso-2-naphthol complexes $(\mathrm{M}=\mathrm{Ni}, \mathrm{Cu}, \mathrm{Cr}, \mathrm{Cd}, \mathrm{Pb})$. J Mol Struct (Thoechem) 775(1-3):29-37

26. West W, Geddes AL (1964) The effects of solvents and of solid substrates on the visible molecular absorption spectrum of cyanine dyes. J Phys Chem 68(4):837-847

27. Liu B, Li W, Wang B, Li X, Liu Q, Naruta Y, Zhu W (2013) Influence of different anchoring groups in indoline dyes for dye-sensitized solar cells: electron injection, impedance and charge recombination. J Power Sources 234:139-146. https://doi.org/10.1016/j. jpowsour.2013.01.152

28. Mulhern KR, Detty MR, Watson DF (2013) Effects of surfaceanchoring mode and aggregation state on electron injection from chalcogenorhodamine dyes to titanium dioxide. J Photochem Photobiol A 264:18-25. https://doi.org/10.1016/j.jphot ochem.2013.04.028

29. Thorat KG, Tayade RP, Sekar N (2016) Acridine-1, 8-diones: A new class of thermally stable NLOphores: photophysical, (hyper) polarizability and TD-DFT studies. Opt Mater 62:306-319. https ://doi.org/10.1016/j.optmat.2016.10.020

30. Kumar S, Ch R, Rath D, Panda S (2011) Densities and orientations of antibodies on nano-textured silicon surfaces. Mater Sci Eng C 31(2):370-376. https://doi.org/10.1016/j.msec.2010.10.015

31. Chepyala R, Panda S (2013) Tunable surface free energies of functionalized molecular layers on Si surfaces for microfluidic immunosensor applications. Appl Surf Sci 271:77-85. https:// doi.org/10.1016/j.apsusc.2013.01.094

32. Tugşuz Arifioglu T, Efeçinar M, Şatiroglu N (2014) A combined first principles TDDFT and experimental study on the UV-Vis spectra properties of $M(p-n i t r o p h e n y l$ azo resorcinol)3complexes (M: Fe, Cr). Turk J Chem 38(1):99-108

33. Becke AD (1988) Density-functional exchange-energy approximation with correct asymptotic behavior. Phys Rev A 38(6):3098-3100

34. Stratmann RE, Scuseria GE, Frisch MJ (1998) An efficient implementation of time-dependent density-functional theory for the calculation of excitation energies of large molecules. J Chem Phys 109(19):8218-8224

35. Frisch MJ (2009) Gaussian 09, Revision C01

36. Hanwell MD, Curtis DE, Lonie DC, Vandermeerschd T, Zurek E, Hutchison GR (2012) Avogadro: an advanced semantic chemical editor, visualization, and analysis platform. J Cheminform. https ://doi.org/10.1186/1758-2946-4-17

37. Salomon O, Reiher M, Hess BA (2002) Assertion and validation of the performance of the B3LYP* functional for the first transition metal row and the G2 test set. J Chem Phys 117(10):4729-4737. https://doi.org/10.1063/1.1493179

38. Cinar M, Karabacak M, Asiri AM (2014) An experimental and density functional study on conformational and spectroscopic analysis of 5-methoxyindole-2-carboxylic acid. Spectrochim Acta Part A Mol Biomol Spectrosc 137:670-676

39. Liu H, Ge C, Yu G, Qian X (2014) Theoretical study of the structural and optical properties of cytosine analogues. Comput Theor Chem 1049:75-81

40. Sharma D, Paterson MJ (2014) The structure and UV spectroscopy of benzene-water (Bz-W6) clusters using time-dependent density functional theory. Photochem Photobiol Sci 13(11):1549-1560

41. Wang Y, Zhang Y, Ni H, Meng N, Ma K, Zhao J, Zhu D (2015) Experimental and DFT studies on the vibrational and electronic spectra of 9-p-tolyl-9H-carbazole-3-carbaldehyde. Spectrochim Acta Part A Mol Biomol Spectrosc 135:296-306

42. Hahn DK, Raghuveer K, Ortiz JV (2014) Computational tests of quantum chemical models for excited and ionized states of molecules with phosphorus and sulfur atoms. J Phys Chem A 118(19):3514-3524

43. Lewińska A, Witwicki M, Bazylińska U, Jezierski A, Wilk KA (2014) Aggregation behavior of dicephalic di-N-oxide surfactants in aqueous solution: experimental and computational approaches. Colloids Surf A 442:34-41

44. Fleming S, Mills A, Tuttle T (2011) Predicting the UV-vis spectra of oxazine dyes. Beilstein J Org Chem 7:432-441

45. Jacquemin D, Perpète EA, Ciofini I, Adamo C (2008) On the TDDFT UV/vis spectra accuracy: the azoalkanes. Theor Chem Acc 120(4-6):405-410

46. Kumar N, Kumar J, Panda S (2015) Sensitivity enhancement mechanisms in textured dielectric based electrolyte-insulator-semiconductor (EIS) sensors. ECS J Solid State Sci Technol 4(3):N18-N23. https://doi.org/10.1149/2.0141503jss

47. Rahman IA, Vejayakumaran P, Sipaut CS, Ismail J, Chee CK (2009) Size-dependent physicochemical and optical properties of silica nanoparticles. Mater Chem Phys 114(1):328-332. https://doi. org/10.1016/j.matchemphys.2008.09.068

48. Li M, Xiao Z, Huan Z, Lu Z (1998) New binding state useful for attachment of dye-molecules onto $\mathrm{TiO}_{2}$ surface. Appl Surf Sci 125(2):217-220

49. Luitel T, Zamborini FP (2013) Covalent modification of photoanodes for stable dye-sensitized solar cells. Langmuir 29(44):13582-13594. https://doi.org/10.1021/la402256v

50. Mulhern KR, Orchard A, Watson DF, Detty MR (2012) Erratum: Influence of surface-attachment functionality on the aggregation, persistence, and electron-transfer reactivity of chalcogenorhodamine dyes on $\mathrm{TiO}_{2}$. Langmuir 28(17): 7071-7082. https ://doi.org/10.1021/la300668k). Langmuir 28(33):12422 
51. Pandit B, Luitel T, Cummins DR, Thapa AK, Druffel T, Zamborini F, Liu J (2013) Spectroscopic investigation of photoinduced charge-transfer processes in $\mathrm{FTO} / \mathrm{TiO}_{2} / \mathrm{N} 719$ photoanodes with and without covalent attachment through silane-based linkers. J Phys Chem A 117(50):13513-13523

52. Bhattacharya S, Srivastava A (2003) Synthesis of gold nanoparticles stabilised by metal-chelator and the controlled formation of close-packed aggregates by them. Proc Indian Acad Sci Chem Sci 115(5-6spec. iss.):613-619

53. Choi D, Rowley JG, Spitler M, Parkinson BA (2013) Dye sensitization of four low index $\mathrm{TiO}_{2}$ single crystal photoelectrodes with a series of dicarboxylated cyanine dyes. Langmuir 29(30):94109419. https://doi.org/10.1021/la401156d

54. Thingna J, Prasad R, Auluck S (2011) Photo-absorption spectra of small hydrogenated silicon clusters using the time-dependent density functional theory. J Phys Chem Solids 72(9):1096-1100
55. Caricato M, Vreven T, Trucks GW, Frisch MJ, Wiberg KB (2009) Using the ONIOM hybrid method to apply equation of motion CCSD to larger systems: benchmarking and comparison with time-dependent density functional theory, configuration interaction singles, and time-dependent Hartree-Fock. J Chem Phys 131(13):134105

56. Liu J, Lu Y (2004) Colorimetric biosensors based on DNAzymeassembled gold nanoparticles. J Fluoresc 14(4):343-354. https ://doi.org/10.1023/B:JOFL.0000031816.06134.d3

Publisher's Note Springer Nature remains neutral with regard to jurisdictional claims in published maps and institutional affiliations. 